\title{
Harnessing the health benefits of plants
}

\begin{tabular}{|c|c|}
\hline $\begin{array}{l}\text { Plant-derived medicines have } \\
\text { been used by humans for } \\
\text { thousands of years. Currently, } \\
\text { there is much focus on } \\
\text { phytocannabinoids, usually } \\
\text { extracted from cannabis } \\
\text { plants. However, these } \\
\text { health-benefitting compounds } \\
\text { can also be found in other } \\
\text { plants. Dr Bianke Loedolff, } \\
\text { Dr Shaun Peters, Ethan } \\
\text { Hunter, Alukhanyo Xonti and } \\
\text { Vincent Malizukiswe Vacu at } \\
\text { Stellenbosch University are } \\
\text { investigating the role of plants } \\
\text { in developing new therapeutic } \\
\text { compounds and enhancing } \\
\text { their phytochemical profiles. } \\
\text { In addition, the research team } \\
\text { are exploring ways to enhance } \\
\text { the existing health benefits of } \\
\text { plants, such as microgreens, } \\
\text { through biofortification }\end{array}$ & $\begin{array}{l}\text { umans have used plants } \\
\text { for medicinal purposes for } \\
\text { thousands of years, with } \\
\text { archaeological evidence suggesting } \\
\text { that this may date back 60,000 years. } \\
\text { Many of the medicines we use today } \\
\text { were first derived from plants, including } \\
\text { aspirin, digoxin, quinine, and morphine. } \\
\text { While herbal drug preparations have } \\
\text { been used for generations, it was only } \\
\text { in the } 19 \text { th century that scientists began } \\
\text { to isolate and extract the compounds } \\
\text { responsible for these health benefits, } \\
\text { giving rise to the development of } \\
\text { synthetic forms of natural products. } \\
\text { However, we still only understand a tiny } \\
\text { amount of what nature may have to } \\
\text { offer us. } \\
\text { Over recent years, there has been a } \\
\text { resurgence of interest in plant-derived } \\
\text { medicines in developed countries, } \\
\text { particularly in compounds derived from } \\
\text { cannabis plants, or hemp (Cannabis } \\
\text { sativa). This is due to the reported } \\
\text { health benefits of phytocannabinoids } \\
\text { (pCBs), bioactive products found in } \\
\text { the resin and flowers of the plant. }\end{array}$ \\
\hline
\end{tabular}

xisting research suggests that $\mathrm{pCBs}$ may act by interacting with human cannabinoid receptors. There are many consequences of this interaction, such as changes in metabolism, appetite, mood, and anxiety, butit is the impact on pain perception and pain pathways

Most studies have focused on PCBs in hemp, but these or similar compounds have also been observed in a few other plants. In particular, offer a rich, undiscovered reservoir of natural therapeutic compounds. One example is the Lion's tail plant (Leonotis leonurus) that is endemic to South Africa. This plant is already used by Indigenous peoples for its medicinal properties and is often used to treat eczema, headaches, and high blood pressure. It has also been reported to induce mild psychoactive hes has already been established that the that are beneficial for health, such

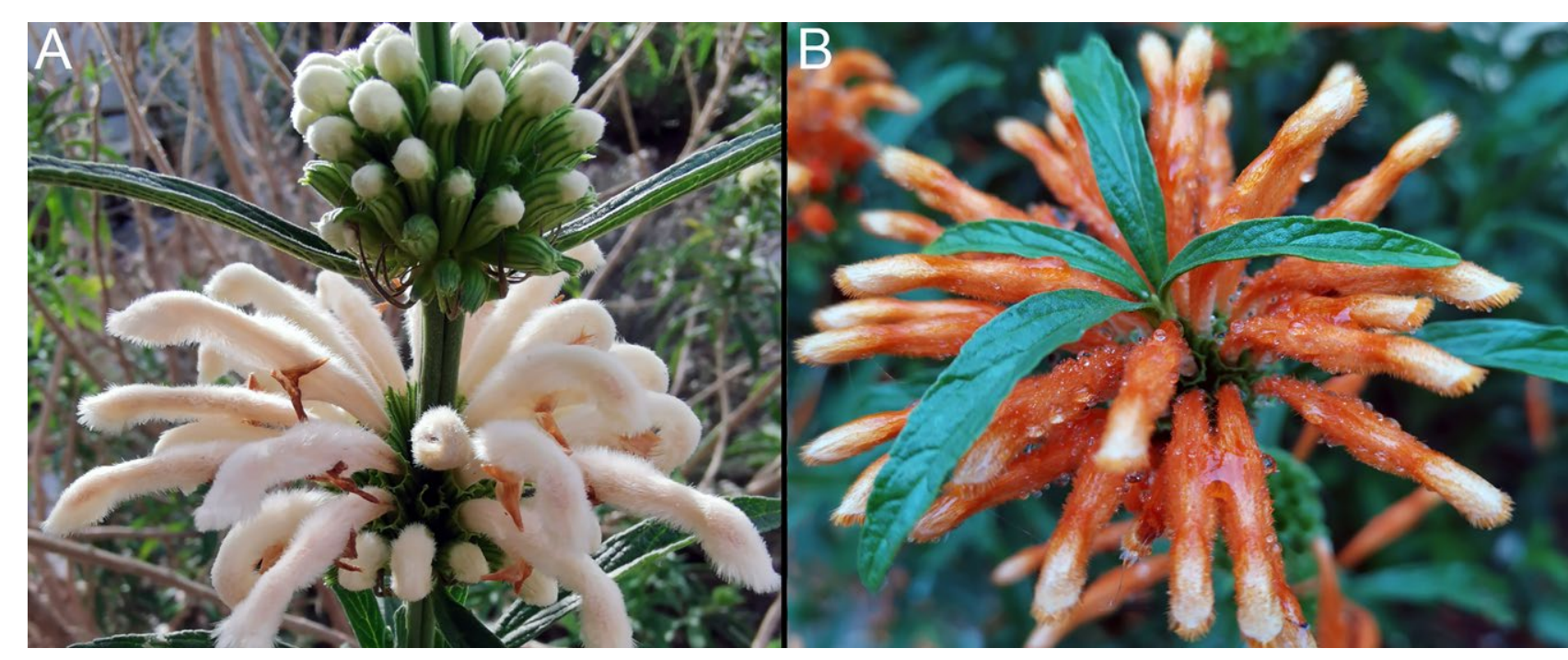

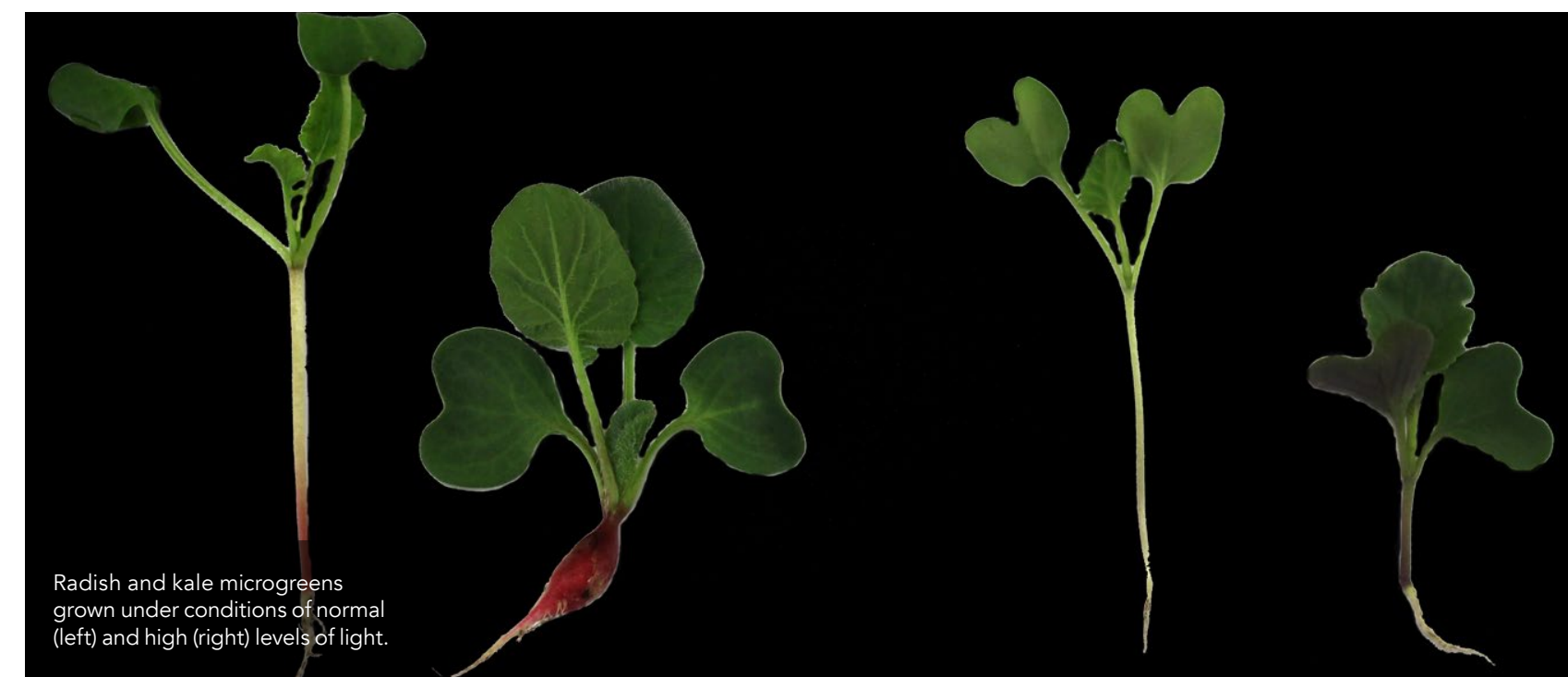

as pCBs, but less is known about the flowers of the plant.

This is something that researchers from Stellenbosch University are vestigating. Dr Bianke Loedolff, Dr Shaun Peters and Ethan Hunter are health benefits of the flowers of two varieties of Leonotis leonurus. Their work will involve extracting metabolites from the flowers and looking for the presence of $\mathrm{PCBs}$, or $\mathrm{PCB}$-like compounds.

FLOWERS O LEONOTIS LEONURUS The researchers were able to characterise Hower extracts using a technique mass spectrometry chemical structures of more about the results from this technique can then be compared with those of existing molecules, to look for similarities and differences in metabolic compounds.

The results of this work showed that the flowers appeared to contain a pCB-like compound called adrenoylEA, a known bioactive compound. Previously, adrenoyl-EA was only thought to be found in mammals but is has very recently been discovered in some plants, too. As it is such a new compound, the is limited data

that they have tentatively identified adrenoyl-EA based on these data, to confirm the exact identity of the compounds found in the flowers.

With a growing global demand for plant-based remedies, particularly those focused on $\mathrm{pCBs}$, identifying high-yielding medicinal crops, such as Leonotis leonurus, provides a possible way to help meet this demand. Furthermore, it provides an alternative, sustainable agricultural crop that could be grown in South Africa, where there is

nd cardiovascular diseases. One way nhich this risk could be reduced is Functional foods are defined as 'foods. that deliver additional benefits over and above their basic nutritional value Examples include foods or drinks that are fortified with vitamins/minerals that they would not naturally contain in high levels. They may provide some health benefits, but should be consumed as part of a varied, balanced diet.

Functional foods contain many bioactive compounds, including polyphenols, phytoestrogens, Humans have used plants for medicinal and carotenoids, purposes for thousands of years, with shown to help archaeological evidence suggesting that non-communicable this may date back 60,000 years. these compounds often insuficient water to farm cannabis 'phytochemicals' and often accumula

$\begin{array}{ll} & \\ \text { in response to stress. Phytochemicals }\end{array}$ ENHANCING PHYTOCHEMICAL PROFILES OF PLANTS Dr Loedolff, Alukhanyo Xonti and colleagues are also exploring possible ways to enhance the phytochemical promote their health benefits.

One of the aims of the World Health Organisation is to reduce mortality rates resulting from malnutrition. Malnutrition is also associated with increased risk of developing non-communicable may function as antioxidants, scavenging free radicals (unstable atoms) that can illness and ageing. They can also help to stimulate the release of bioactive the gut microbiome (bacteria and other

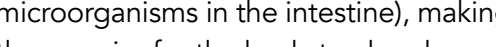
the body to absorb.

BIOFORTIFICATION OF MICROGREENS Microgreens are seedlings with two to four true leaves that are packed
full of phytochemicals: up to 100 compounds from digested food, via 


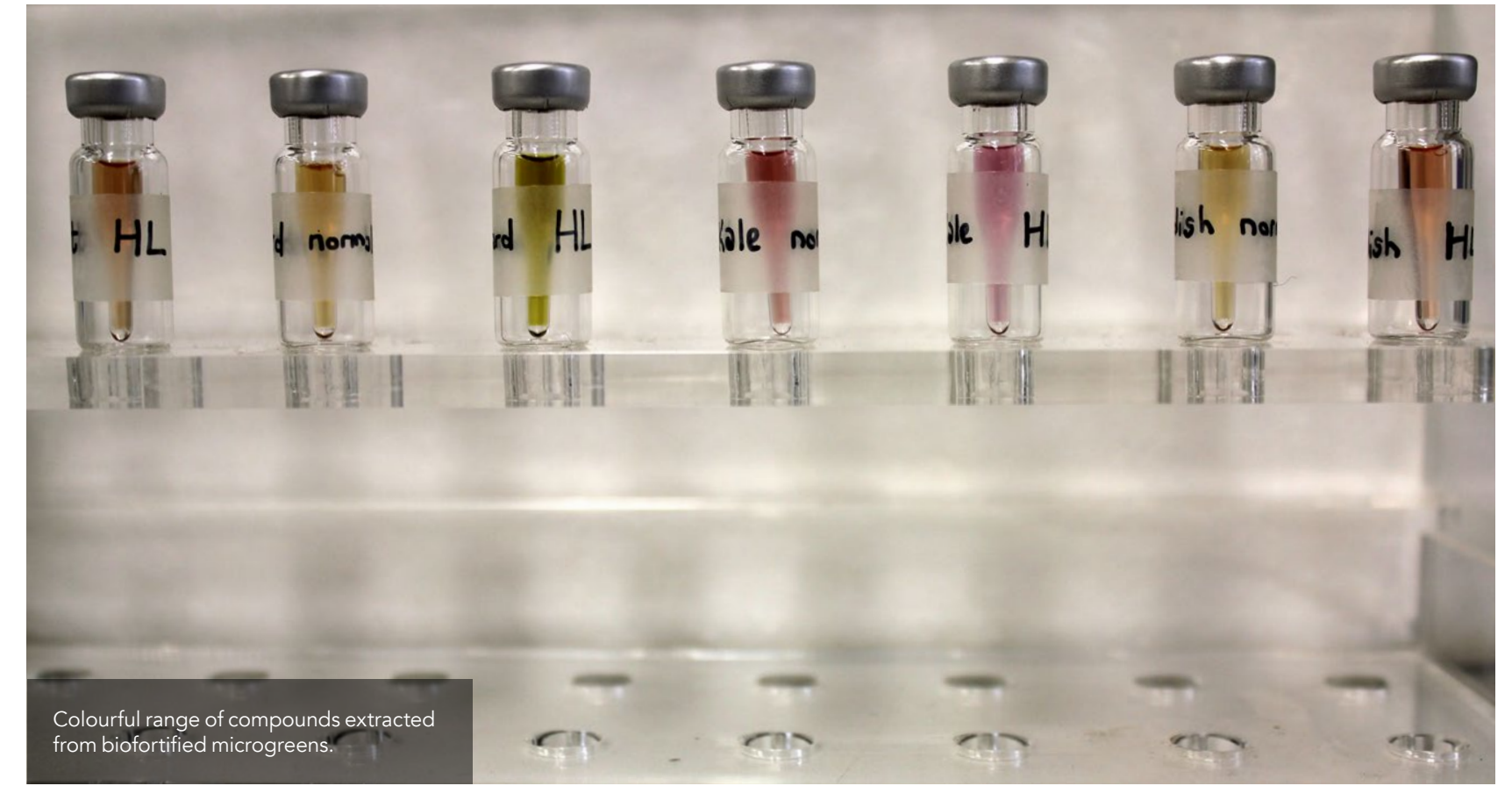

times more than in mature plants. Since phytochemicals accumulate in response to stress, placing plants under
controlled environmental stressors, such as light and temperature, can artificially enhance the production. and accumulation of these bioactive compounds. This is often called biofortification. Older plants have time to adapt to their environment and rely on alternative stress response pathways.

The team at Stellenbosch University aimed to augment the accumulation of phytochemicals in microgreens (kale and
radish) by exposing them to very high seedlings were The in a normal- or highlight environment. The normal group were exposed to 16 hours of light at 70 umol photons $\mathrm{m}^{-2} \mathrm{~s}^{-1}$ (a measurement based on the number of photons in particular area, over a particular time. whereas the high-light-intensity group were grown in $270 \mu \mathrm{mol}$ photons $\mathrm{m}^{-2} \mathrm{~s}$

Firstly, the researchers noticed that the plants looked visibly different, with those grown under high-light intensity showing stunted stem development, broader leat su
area and purple colouration.
Total antioxidant capacity was units, as vitamin $E$ is known to be potent antioxidant. Total antioxidant capacity increased in both types of microgreens when grown under environmental stress. Using tandem mass spectrometry, the researchers were able to show the levels of antioxidant compounds produced by light conditions.

In a similar study, Dr Loedolff and collegues previously demonstrated

intensity. However, it is important to bear in mind that this was done using human DNA in the laboratory, rather than using cells derived from humans, or human subjects.

\section{MINI AND MIGHTY}

viously thought of as a culinary garnish, are now becoming a speciality crop with proven health a using these plants over others is the short time between planting and
harvesting, approximately $10-25$ days. a culinary garnish, are now becoming research team a speciality crop with proven health sustainable benefits.

that it was possible to biofortify wild rocket with an antioxidant compound called resveratrol, a phytochemical that had not previously been documented in this plant.

But how does this translate to visible health benefits? The researchers also was protected from oxidative stress if high concentrations of plant extracts were used, regardless of whether they the plants were increased under highshowed that human genomic DNA

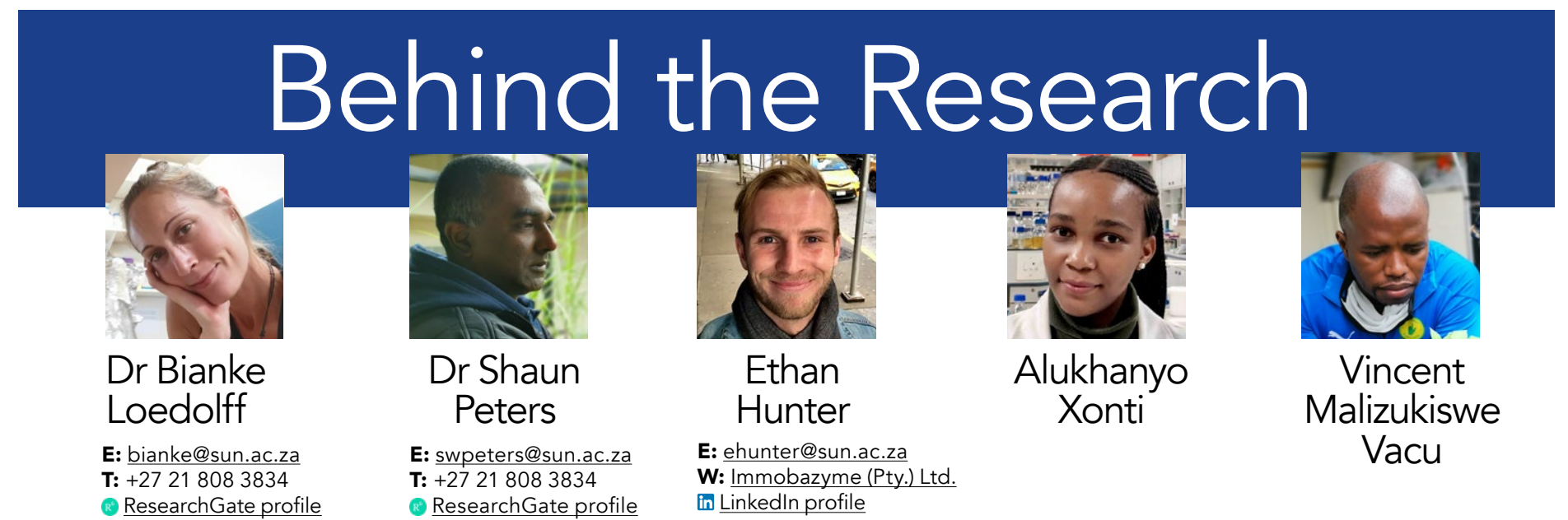

Research Objectives

The researchers investigate exotic indigenous plants from South Africa for the development of new therapeutic compounds and to enhance

\section{Detail}

Institute for Plant Biotechnology

Faculty of Agrisciences
Stellenbosch University

W: www.sun.ac.za/english/faculty/agri/plant-

Bio

Bianke Loedolff holds a PhD from
Stellenbosch University (South Africa)

and has a special interestin human health

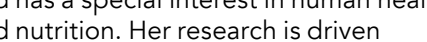

through communication, and she regularly
features on international panel discussions seeking solutions to achieve Sustainable Development Goal \#2, ending hunger and
malnutrition in developing countries.

Shaun Peters holds a PhD from the

a specialty in carbohydrate physiology in
plants and microbes. He is currently affiliated to the Institute for Plant Biotechnology

(Stellenbosch University, South Africa)
running a research team and involved in the
curriculum of

Ethan Hunter holds an MSc from

passed with merit. He is currently co-founder and COO of Immobazyme (Pty Ltd), a

proudly Soln Afican company pioneering
the biotechnology industry with innovative technologies. He has a special interest in using plants for therapeutics development. Alukhanyo Xonti is currently reading for
an MSc degree at Stellenbosch University (South Africa). Her passion for human

member of this research team and, while pursuing her tertiary degrees, she
regularly participates in peer-training and

Vincent Vacu holds an MSc from Jilin currently reading fisty (China) and is Stellenbosch University (South h ffrica). His invaluable to the team and he regularly participates in peert.
other than his ow

Funding

Collaborators

- Prof Sharon Prince

\section{References}

- Loedolff, B, Brooks, J, Stander, M, Peters, S, Kossmann, J, (2017) in Diplotaxis tenuifolia (wild rocket) micro-greens. Functional Foods in Health and Disease, $7(11)$, 859-872. doi.org/10.31989/fthd.

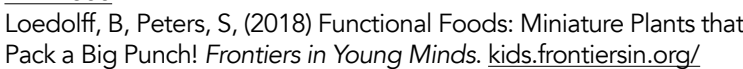
articles/10.3389/ffrym.2018.00052 - Hunter, E, Stander, M, Kossmann, J, Chakraborty, S, Prince, S, he identification of a medicinal plant (Leonotis leonurusus. BMC research notes, 13(1), 522 . doi.org/10.1186/s13104-020-05372Xonti, A, Hunter, E, Kulu, N, Maboeei, P, Stander, M, Kossmann,
J, Peters, S, Loedolff, B, (2020) Diversification of health-promoting phytochemicals in radish (Raphanus raphanistrum) and kale (Brassica Foods in Health and Disease, 10(2), 65-81. doi.org/10.31989/ffhd v10i2.681

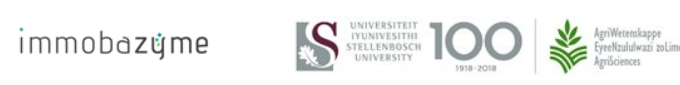

\section{Personal Response}

Although higher levels of phytochemicals accumulate in microgreens ander high-light condhions, how does this compounds transferred to the human body to fight disease, or are the additional phytochemicals lost during
digestive processes?

II Phytochemicals generally have a low bioavailability
in our body and much of it will be excreted, regardless. Therefore, we need a sustained intake of fruits and vegetables to remain healthy. A little goes a long way in the
microgreen world. Unlike mature vegetables, we only need to consume a handful of microgreens to ensure our daily reduced chronic inflammation and prevention of the nonfight disease effectively, we need high concentrations and a diverse range of phytochemicals (often not found in mature vegetables and fruts frym from
achieved through biofortification of microgreens. 